\title{
About the Artist: Maika'i Tubbs
}

\section{M}

aika'i Tubbs began making art from recycled trash in New York, where he noticed trash bags piled as tall as him appearing and disappearing daily. Having earned a BFA in painting from the University of Hawai'i at Mānoa in 2002, he moved to New York for graduate studies at Parsons School of Design, where he completed an MFA in 2015. Much of his early work includes sculpture and installations with melted and repurposed plastics, whose color and sheen remain in the finished work. More recent installations

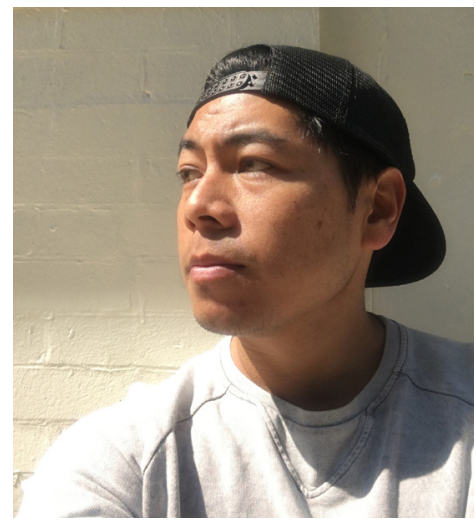

Рhoto COURTESY OF THE ARTIST include rocks made from fusions of beach plastic, cigarette butts, cardboard, plastic shopping bags, Styrofoam, and other trash materials, inspired by "plastiglomerate," an anthropogenic stone that geologists identify as a by-product of human pollution. Currently based in Brooklyn, Tubbs was born in Hawai'i, where this agglutinate marker of the current Anthropocene epoch is a startling reminder of man's impact on the environment, especially where it is found accumulating in coastal areas such as Kamilo Beach on the island of Hawai'i and Kahuku Beach on O'ahu.

Seductive and conceptually challenging, Tubbs's work confronts us with our complicity as consumers in cycles of waste and overconsumption. It also reminds us of the necessity to unlock creative potential to solve some of the problems that confront us today. His work has been represented in numerous national and international shows and is featured in permanent collections of the Landesmuseum Hannover in Germany, the National Gallery of Canada in Ottawa, the Honolulu Museum of Art, and the Hawai'i State Foundation on Culture and the Arts, State of Hawai'i Permanent Collection. For more information, please see maikaitubbs.com.

MOANA NEPIA

The art featured in this issue can be viewed in full color in the online versions. 


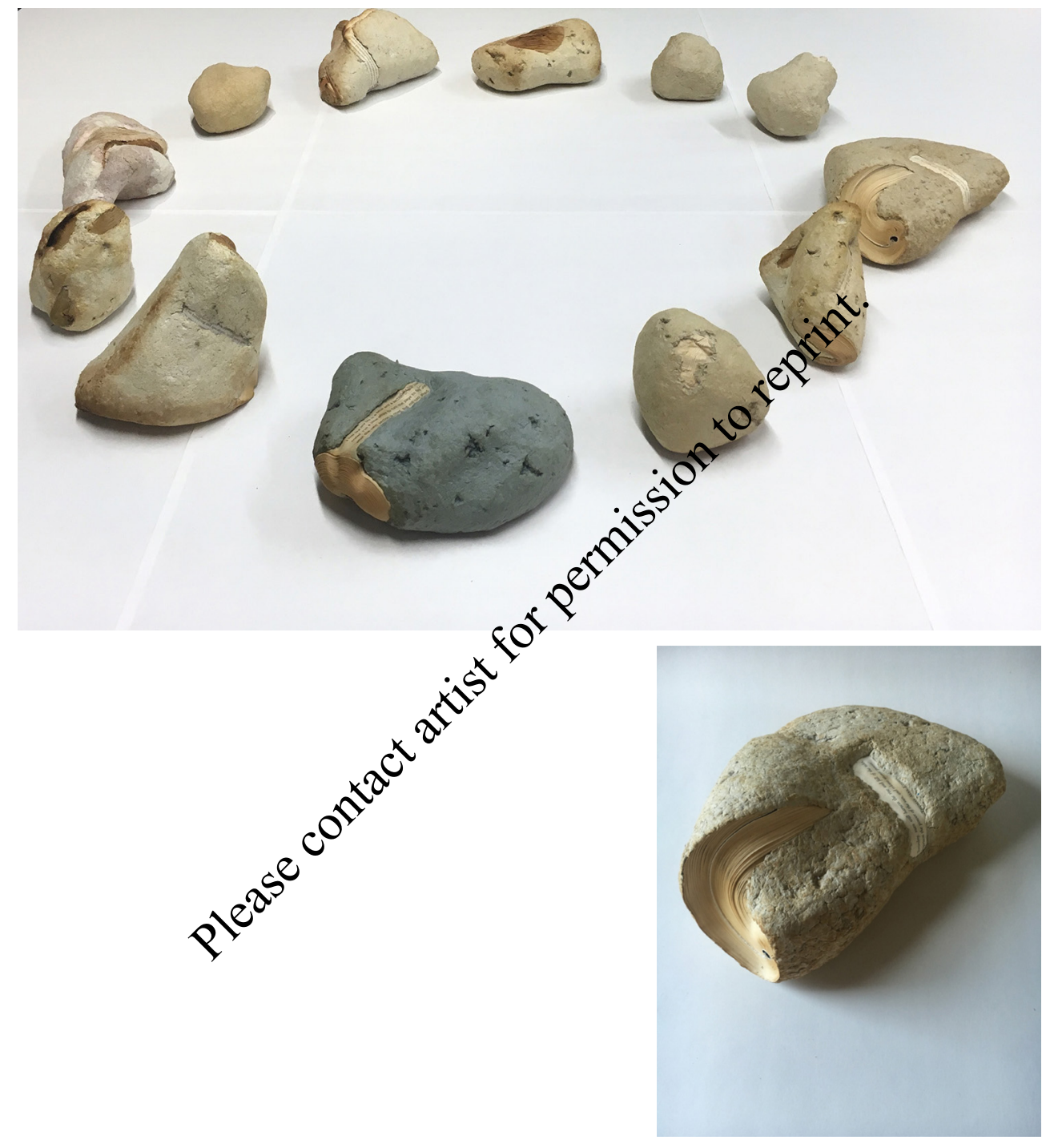

Written in Stone (installation and detail views), by Maika'i Tubbs, 20 I6.

Twenty-four books, $4^{\prime} \times 4^{\prime} \times I^{\prime}$. Photo courtesy of the artist.

Tubbs asks, "Are books the literary equivalent of cassette tapes in the digital age, or will their tactile qualities save them from extinction?" Each stone in this work is made from two books collected on New York City curbsides. One book and knowledge source is obliterated to encase and protect the pulped remains of another, creating metaphorical summations of the originals-hybrids that lure the curious into discovering what lies within the hidden pages. Sheets of text protrude through the stone, reminding us of their origins and pointing to the evolution of our changing environment. 


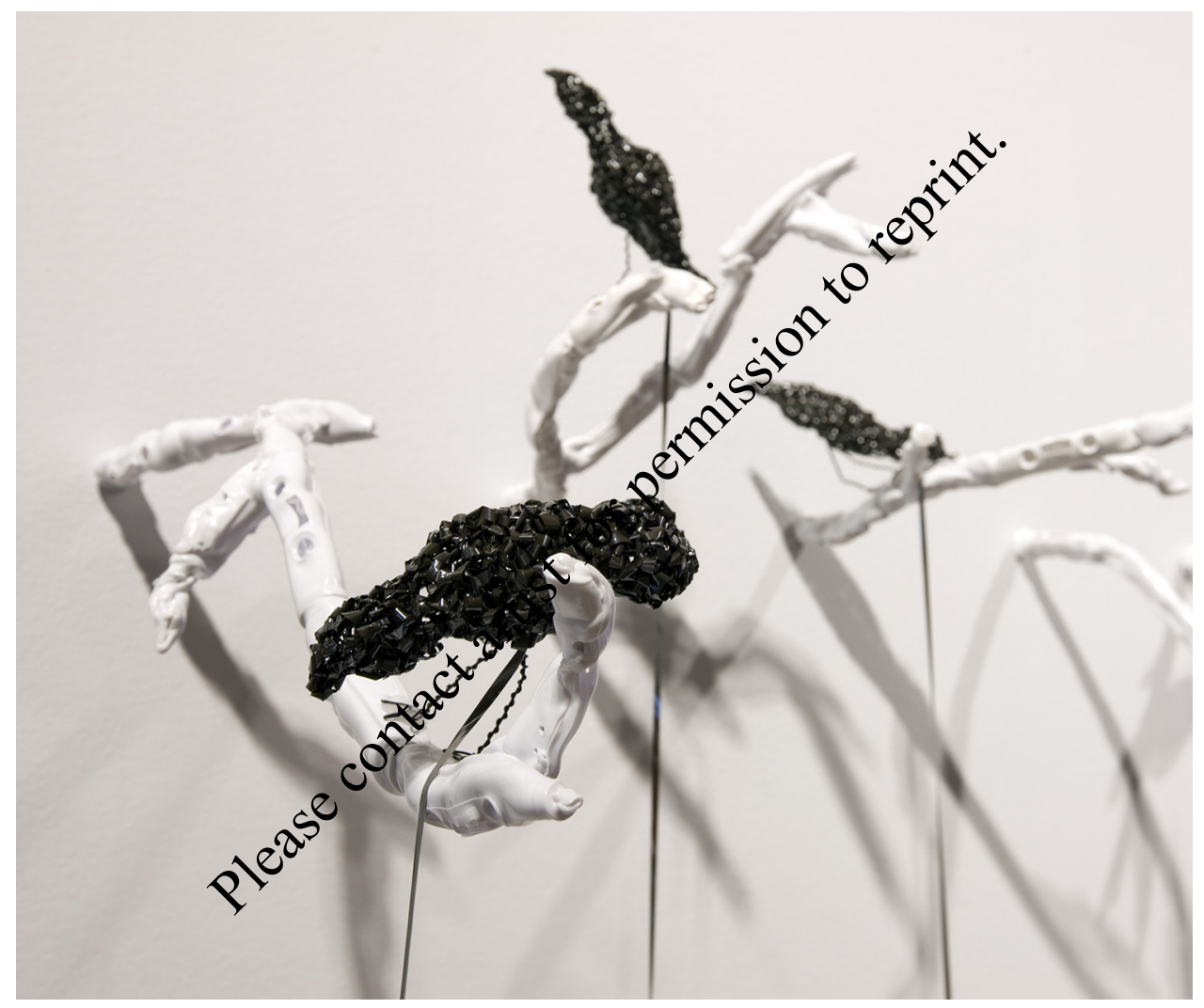

Erasure (detail), by Maika'i Tubbs, 2008.

Audiocassette magnetic tape and casings, wire, I $3^{\prime} \times 6^{\prime} \times$ I. $5^{\prime}$. Photo by Shuzo Uemoto.

This sculpture installation comprises sixteen ' $\overline{0}$ ‘o birds (black honeyeater, Moho nobilis), woven out of magnetic tape sitting on branches made from audiocassette tape casing. Yellow ' $\overline{0}{ }^{\complement} \bar{O}$ feathers were used in traditional Native Hawaiian capes until predation by introduced animals and loss to diseases following Western contact led to the species' extinction. Each bird in the installation unravels into a pile of tape below with a tiny magnet attached to the end. The magnets are small and unassuming, like the first mosquitoes brought to the islands, but they also have the potential to slowly erase the magnetic tape, leaving no data behind. 


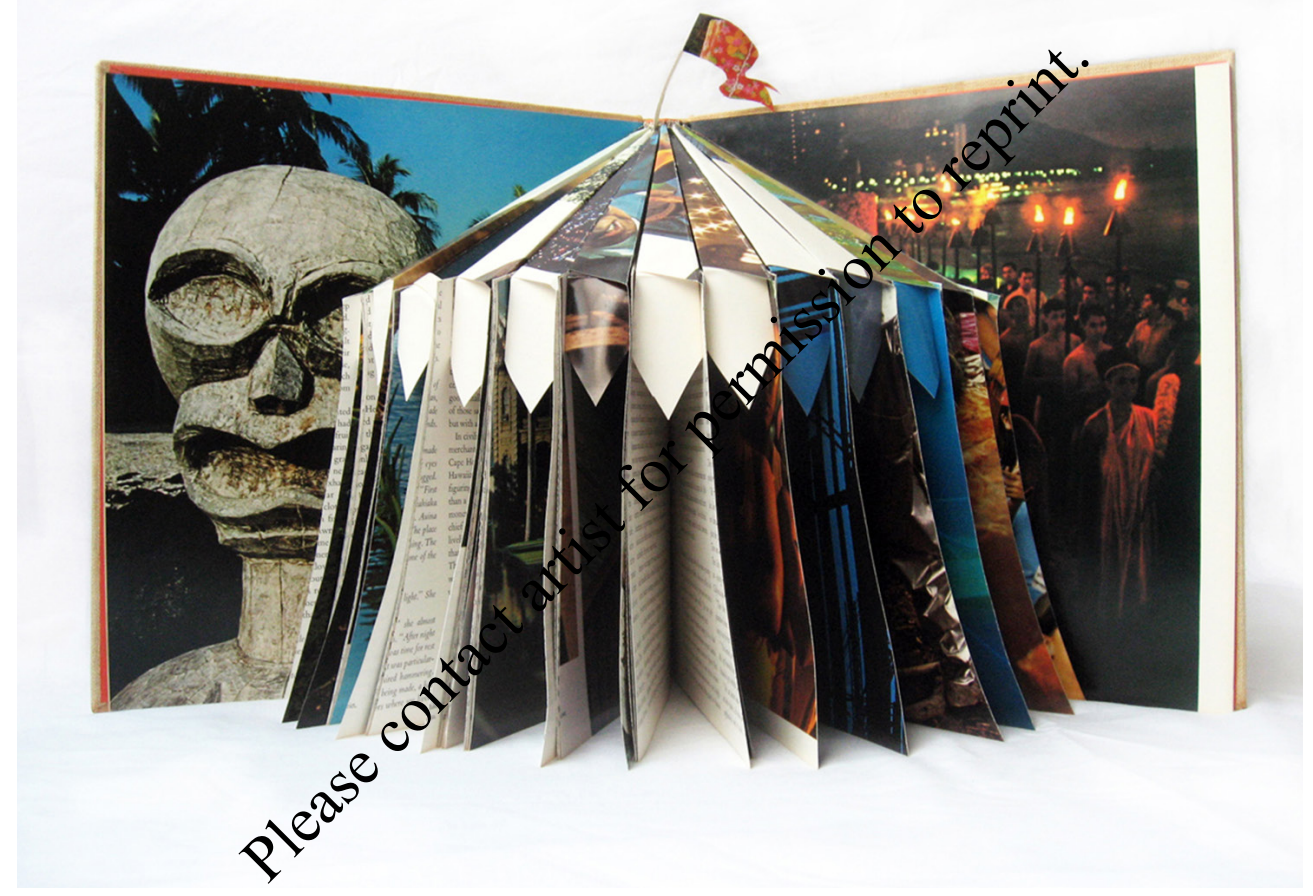

Next Show in Fifteen Minutes, by Maika'i Tubbs, 2008.

The Hawaiians (I970 book by authors Gavan Daws and Ed Sheehan and photographer Robert B Goodman), I 5 " $\times$ IO" $\times 8$ ". Photo courtesy of the artist.

Next Show in Fifteen Minutes is a performance that looks at stereotypical depictions of Native Hawaiians and expectations sometimes placed on them to perform "on command." In this performance, Tubbs picks up a book from a pedestal, opens it, and folds the pages into a circus tent while singing in Hawaiian. He then unfolds the pages, closes the book, and repeats the performance after fifteen minutes. 


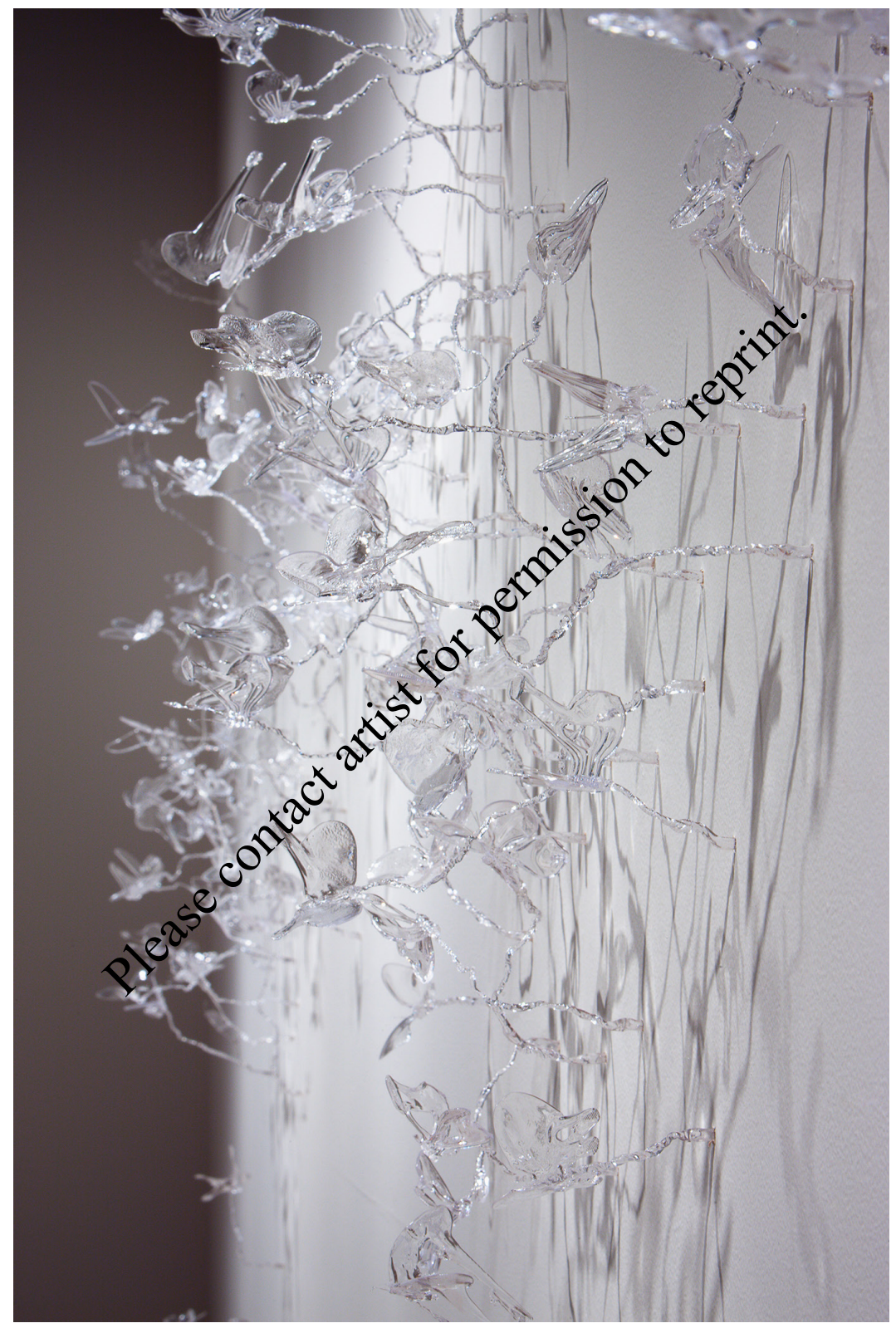

At Your Disposal (installation detail), by Maika'i Tubbs, 2009.

Plastic forks, spoons, knives, 9' x 27' X I'. Photo by Brad Goda. Tubbs made this work in response to a moment in the Hawaiian tale of Hi'iakaikapoliopele when the demigod Mahiki commanded the spirits of the forest (in the forms of butterflies) to attack her. He likens the way Mahiki treated the spirits to the way people think about single-use plastic-as disposable tools. 


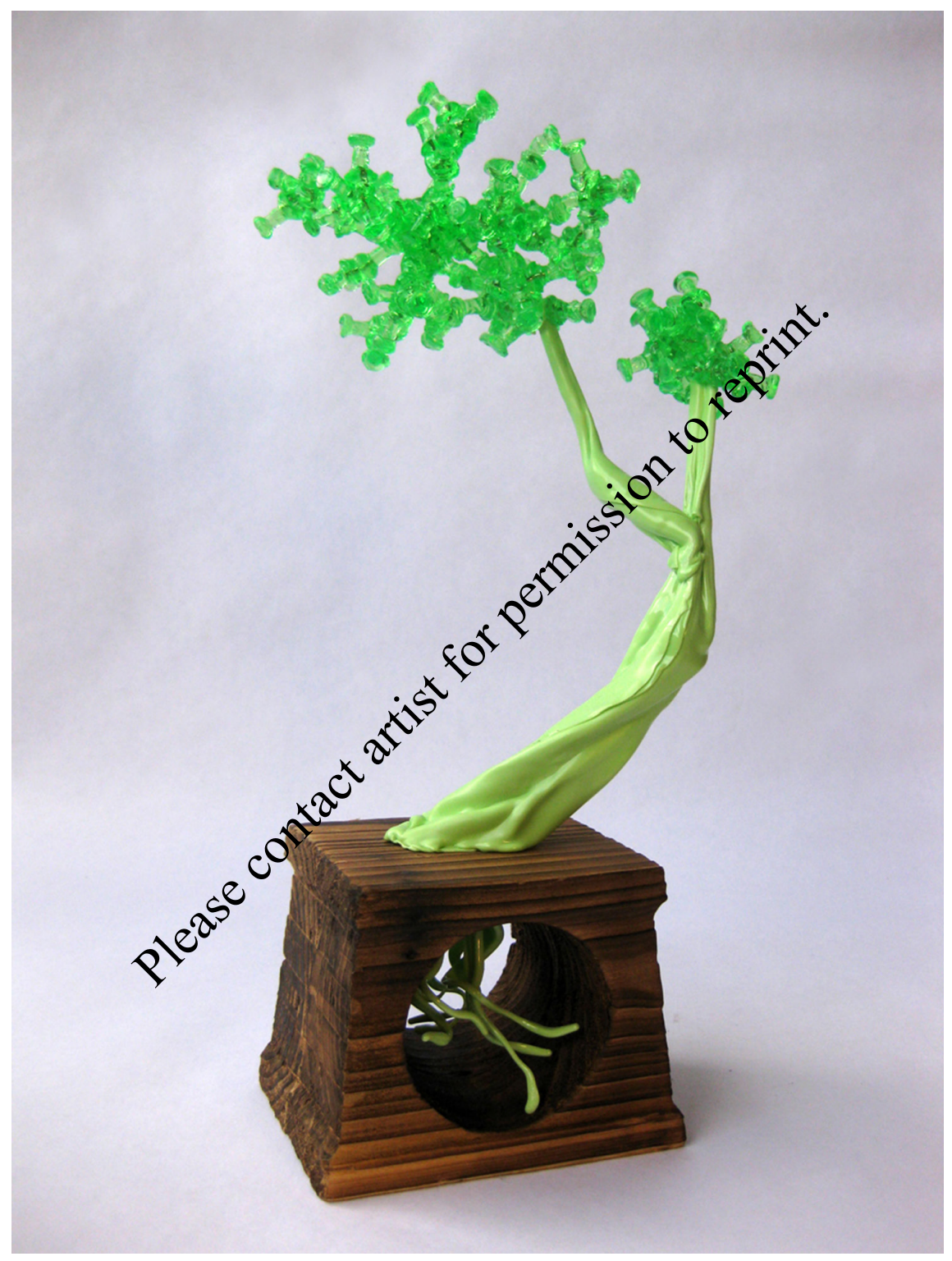

Homegrown, Green \# ${ }_{I}$, by Maika'i Tubbs, 2009.

Push pins, plastic plates, forks, wood, 5 " $\times$ I I. $5 " \times 3 "$.

Photo courtesy of the artist.

This work is one of a series of miniature trees Tubbs made from office supplies while thinking about the way we may yearn for nature, try to control it, and sometimes force it to dwell in places we do not wish to be. 


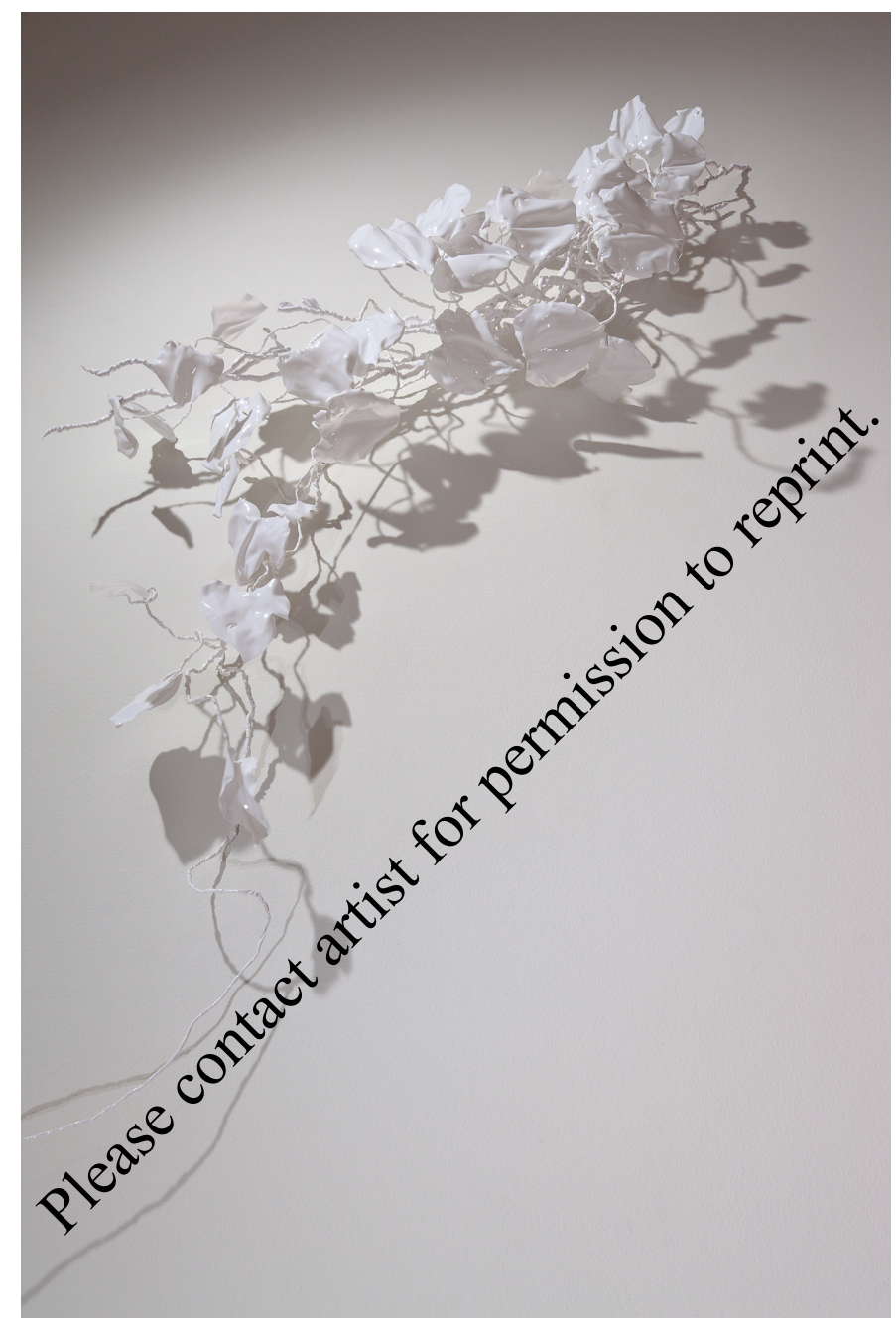

A Life of Its Own (installation detail), by Maika'i Tubbs, 2010.

Plastic forks, spoons, knives, plates, $23^{\prime} \times 15^{\prime} \times 9^{\prime}$.

Photo by Brad Goda.

A Life of Its Own is an installation that draws parallels between the prevalence of plastic and the invasive spread of the woodrose vine in Hawai'i. Tubbs explains, "While both are beautiful and appear harmless, the vine takes over acres on four of our islands and snuffs out native plant life, while plastic permeates through our daily lives and fills limited landfill spaces." Vines in the installation appear to "overtake the space, announcing plastic prominence and the widespread disposable culture that plagues the islands." 


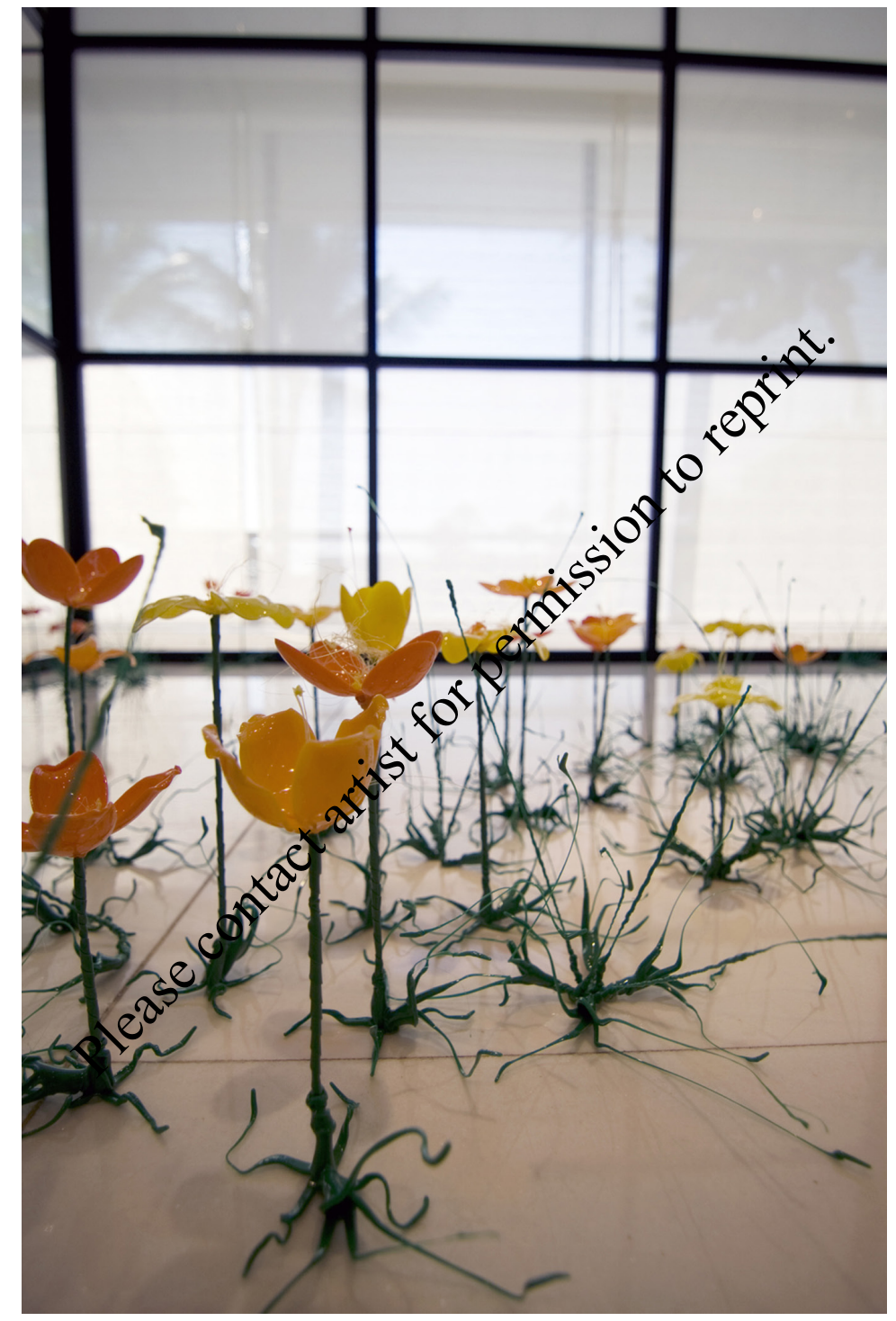

Poppy Culture (installation detail), by Maika'i Tubbs, 20 го.

Plastic spoons, plates, forks, 9' $\times 9^{\prime} \times I^{\prime}$.

Photo courtesy of the artist.

Tubbs's fifty poppy flower sculptures installed in this floor work, without a barrier to protect them, offer a chance for the public "to accidentally trample and help in the migration of plastic 'seeds' throughout the gallery." In "finding bits of plastic scattered in our everyday landscape," he imagines how "they might be seen as the beginning stage of natural plastic growth patterns.” 


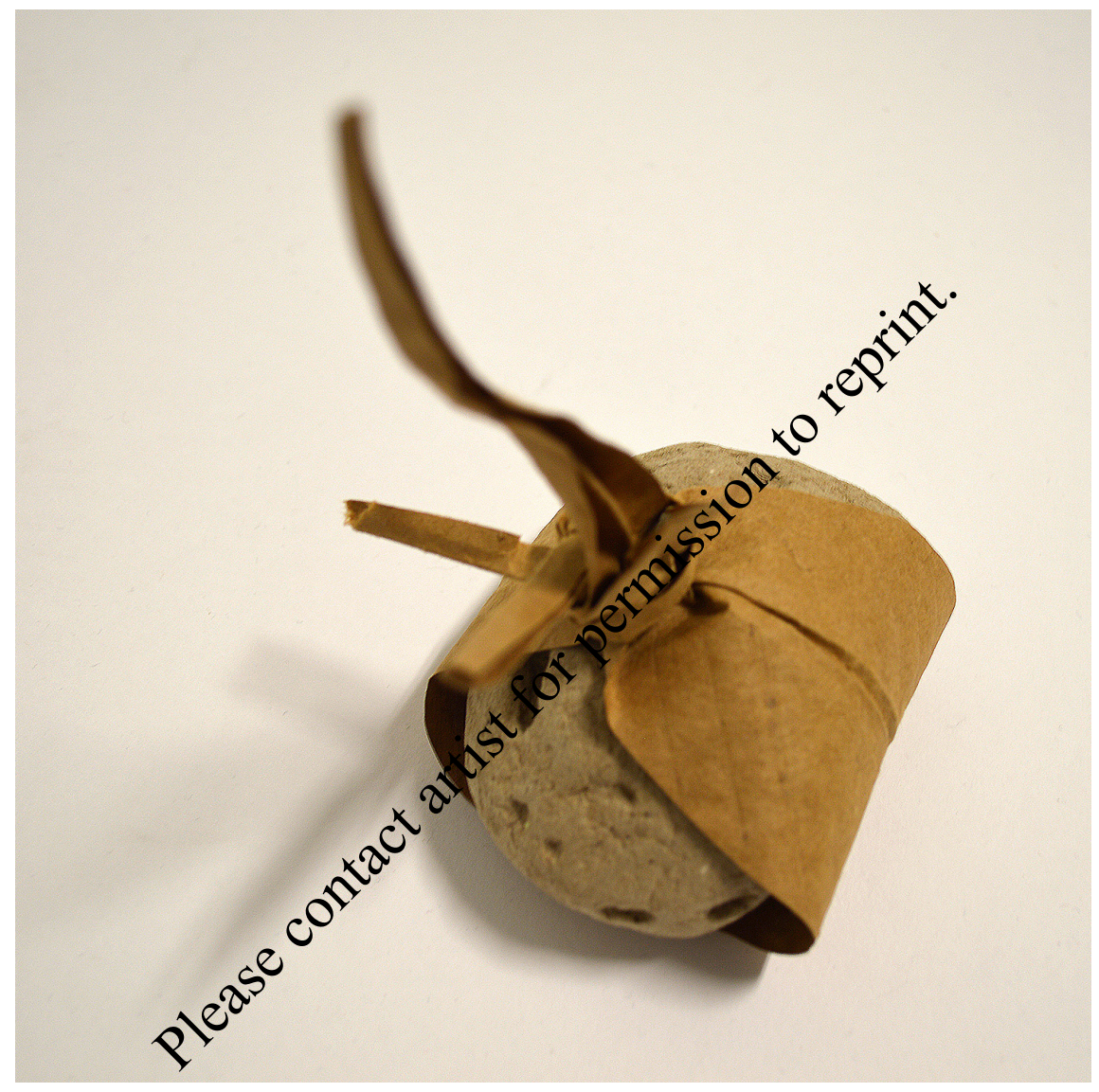

In Return, by Maika'i Tubbs, 2014 .

Cardboard, $3^{\prime} \times 5^{\prime} \times 8^{\prime}$. Photo courtesy of the artist.

While watching people add waste to garbage mounds in

New York, Tubbs remembered how tourists sometimes add stones wrapped in leaves to random roadside sites in Hawai' $i$, perhaps in the mistaken belief they are following a Native Hawaiian sacred practice. He decided to replicate this ritual through transforming a worn-out cardboard box, found along the East River near his neighborhood in Brooklyn, into a stone wrapped in leaf, before returning it to Hawaici. 


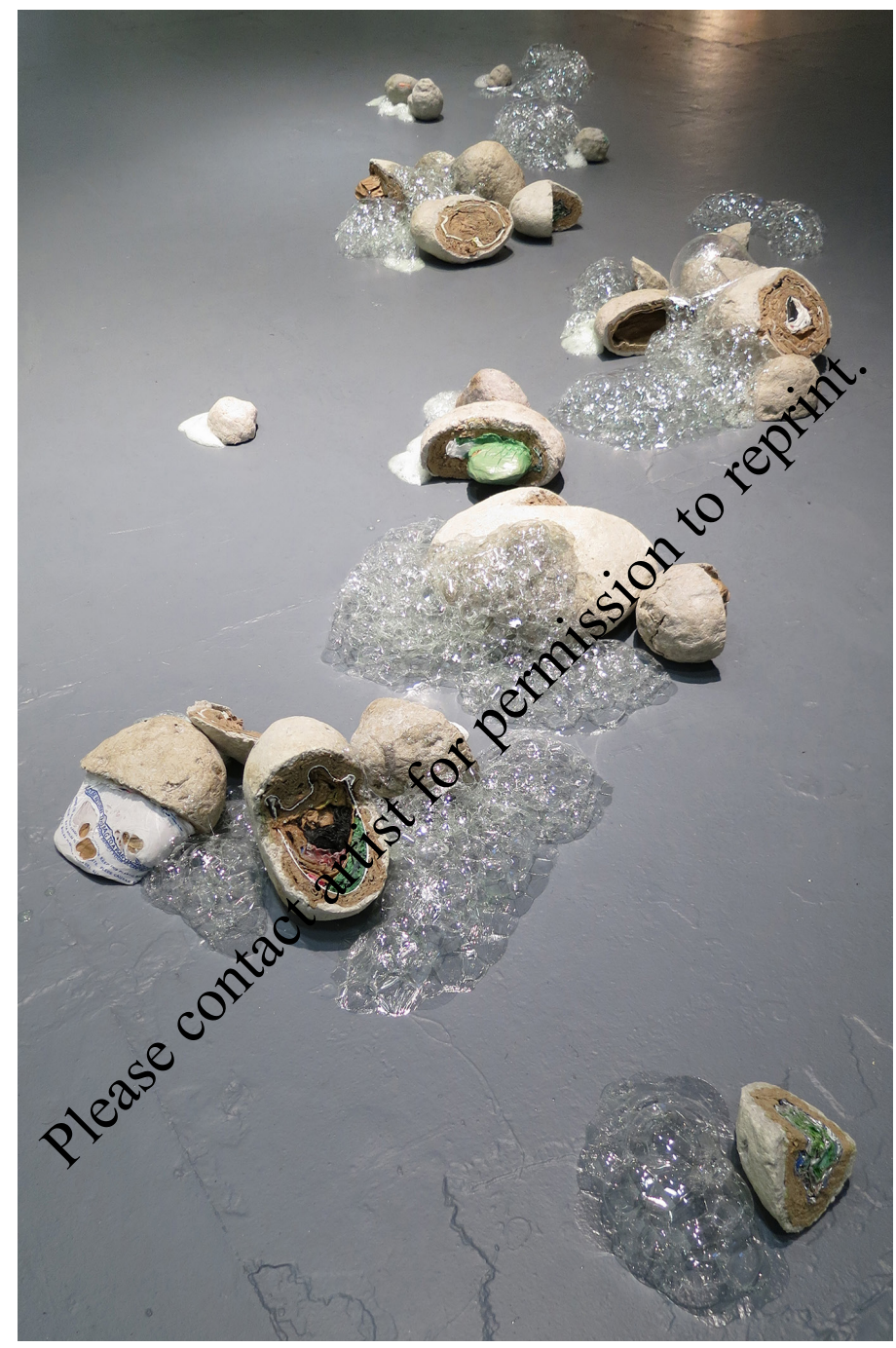

Stepping Stones, by Maika'i Tubbs, 2015.

Plastic shopping bags, cardboard, paper plates, cigarette butts, posters, food wrappers, plastic containers, junk mail, paper towels, posters, parking tickets, napkins, fliers, Styrofoam, yarn, videocassette tapes, plastic marine debris, $3^{\prime}$ X I4 ' X I'. Photo courtesy of the artist.

Using trash from the streets of New York City and the beaches of O'ahu, Tubbs creates idealized rock forms "sliced and displayed as trash geodesas a fossil record for the future along an imaginary shoreline. Referencing pollution's impact on natural seafoam, the stones sit within gelatin bubbles that last a few weeks before flattening out to resemble plastic saran wrap that glows in the dark when exposed to ultraviolet light, creating a radioactive hybrid setting for the stones in this futuristic shoreline." 